\title{
Performance Study of the Glass Vacuum Tube Photovoltaic/Thermal Heat Pump System
}

\author{
Hongbing Chen ${ }^{\mathrm{a} *}$, Ping Wei ${ }^{\mathrm{b}}$, \\ ${ }^{a}$ Beijing University of Civil Engineering and Architecture, 1 Zhanlanguan Road, Beijing 100044, China \\ ${ }^{b}$ Beijing Polytechnic College, 106 Shimen Road, Beijing 100048, China
}

\begin{abstract}
Many studies found that the decrease in photovoltaic (PV) cell temperature by $10{ }^{\circ} \mathrm{C}$ can improve the efficiency by $0.5-0.7 \%$ based on the reference efficiency of $15 \%$. In this paper, the refrigerant R134a is used to cool down the PVs and thus improve the efficiency. The novel glass vacuum tube PV/thermal (PV/T) panel, made of 6 glass vacuum tube - PV module - aluminium sheet - cooper tube sandwiches connected in series, is coupled with a heat pump system acting as the evaporator. Numerical models are established for the performance study. The simulation results indicate that the electrical efficiency is mainly affected by the solar radiation, while the thermal efficiency is mainly affected by the ambient temperature. The annual mean thermal efficiency, electrical efficiency and COP are 0.659, 0.136 and 3.8, respectively.
\end{abstract}

Keywords: Photovoltaic/thermal (PV/T) collector, heat pump, COP

\section{Introduction}

Photovoltaic (PV) technology has been widely used for generating electricity. However, the PV modules are inefficient in terms of solar-to-electricity conversion efficiency, about $10-17 \%$ for most commercial mono-crystalline and poly-crystalline silicon PV modules [1]. Many studies found that the PV cells' working temperature had an important impact on the electrical efficiency. In order to improve the electrical efficiency, many researchers employed air [2-3] or water [4-6] to cool down the PV modules, and the heat extracted from the PVs was used for space heating or domestic hot water supply. Ji et al. [7] used the refrigerant R22 to cool down the flat plat PV modules and found the electrical efficiency and thermal efficiency were above $12 \%$ and $50 \%$ during the testing period.

Most of the above studies were using air or water for the cooling of traditional flat plate PV modules. In this study, the refrigerant R134a is employed for the cooling of glass vacuum tube (GVT) PV modules and the PV modules is coupled with a heat pump system. With the low evaporating temperature, it is expected to achieve a better cooling effect of the PV modules, and thus a better electrical performance will be reached. Meanwhile, the glass vacuum tube PV/thermal (PV/T) collector will decrease the heat loss to the air compared with the conventional flat plate PV/T collector, resulting in the increase in thermal efficiency. Performance study of the GVT PV/T heat pump system is carried out in this study.

\section{System Descriptions}

The novel GVT PV/T heat pump system comprises four main parts: compressor, expansion valve, water-cooled condenser and PV/T collector/evaporator as well. The GVT PV/T evaporator, made of 6 glass vacuum tube - PV module - aluminium sheet - cooper tube sandwiches connected in series, is the

\footnotetext{
* Manuscript received July 25, 2012; revised September 10, 2012.

Corresponding author. Tel.: +86-10-68322517; fax: +86-10-88361680; E-mail address: chenhongbing@bucea.edu.cn.
} 
key part of the system. Fig.1 shows a cross-sectional view of the sandwich tube. It is made of an aluminium sheet which adhered on the back of the PV module for heat extraction; the sandwich is placed at the centre of the glass vacuum tube. Three quarters of the u-shape copper tube's external surface is tightly rolled with the aluminium sheet at the side-ends along the cooper tube providing a good surface contact between the aluminium sheet and the copper tube. This enables a good heat transfer from the aluminium sheet to the refrigerant. The characteristic dimensions of the GVT PV/T panel are shown in Table 1.

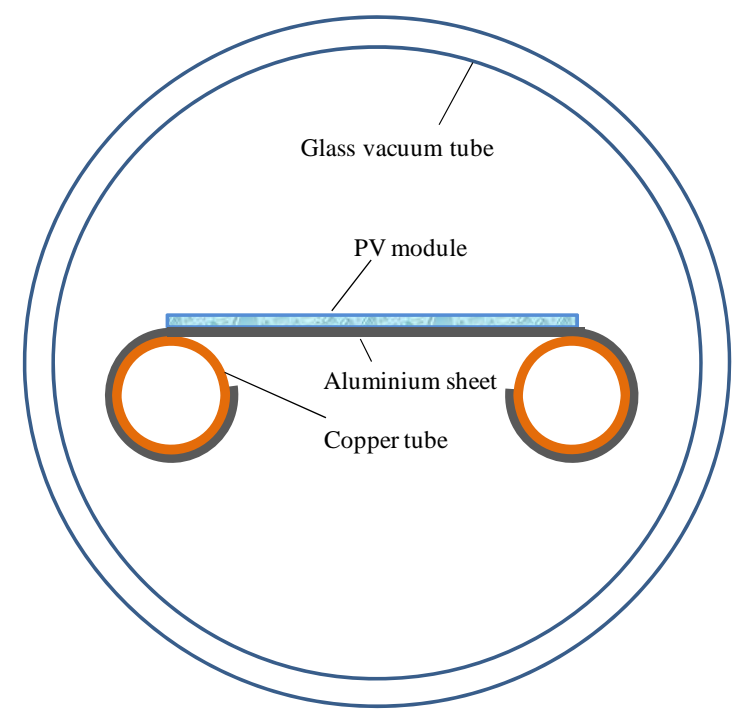

Fig. 1. Cross-sectional view of a glass vacuum tube

Table 1. Characteristic dimensions of the GVT PV/T panel (mm)

\begin{tabular}{lll}
\hline Component & Parameter & \\
\hline \multirow{3}{*}{ glass vacuum tube } & length & 1,000 \\
& external diameter & 70 \\
& internal diameter & 58 \\
length & 800 \\
PV module & width & 40 \\
& thickness & 4 \\
aluminium sheet & length & 800 \\
& width & 55 \\
& thickness & 1 \\
copper tube & external diameter & 8 \\
& internal diameter & 6 \\
& length & 12,000 \\
\hline
\end{tabular}

\section{Numerical Models}

Zondag et al. [8] built four numerical models for the simulation of PV/T collector: a 3D dynamical model and three steady state models that are 3D, 2D and 1D. The study showed that the 1D steady state model performed almost as good as the others. Ji et al. [9] presented a dynamic model of the PV evaporator in a PV/T solar-assisted heat pump. The simulation results indicated that there was very small temperature difference distributed at the layers of PV module, aluminium sheet and refrigerant (neglecting the last small length of overheating) respectively. Therefore, for this work, the 1D steady state model is used for the simulation based on the following assumptions:

- The PV/T heat pump system is in quasi-steady state.

- The heat loss of the PV/T heat pump system is neglected. 
- The pressure drop of the PV/T heat pump system is neglected.

- A mean temperature is assumed across each layer of the PV/T panel.

Based on the energy balance analysis of each component of the two PV/T panels and other components of the heat pump system, mathematic models are established for the numerical simulations on energy performance study.

The heat balance at the external tube is given by

$$
0=\beta_{o g} G\left(A_{o g} / 2\right)+q_{r, i g-o g} A_{i g}+q_{d, i g-o g} A_{i g}-q_{r, o g-s k y}\left(A_{o g} / 2\right)-q_{v, o g-a} A_{o g}
$$

where $\beta_{o g}$ and $A_{o g}$ are the absorptance and surface area of the external tube "og", respectively; $G$ is the solar radiation; $A_{i g}$ is the surface area of the internal tube "ig"; $q_{r, i g-o g}$ and $q_{d, i g-o g}$ are the heat radiation and conduction from internal tube "ig" to "og", respectively; $q_{r, o g-s k y}$ is the heat radiation from "og" to the sky; $q_{v, o g-a}$ is the heat convection from "og" to the air.

The heat balance at the internal tube is given by

$$
0=(\beta \tau)_{i g} G\left(A_{i g} / 2\right)+q_{r, p-i g} A_{p}+q_{d, p-i g} A_{p}+q_{r, a l-i g} A_{a l}+q_{d, a l-i g} A_{a l}-q_{r, i g-o g} A_{i g}-q_{d, i g-o g} A_{i g}
$$

where $(\beta \tau)_{i g}$ is the effective absorptance of the "ig"; $q_{r, p-i g}$ is the heat radiation from the PV module "p" to "ig"; $q_{d, p-i g}$ is the heat conduction from "p" to "ig"; $q_{r, a l-i g}$ is the heat radiation from the aluminium sheet "al" to "ig"; $q_{d, a l-i g}$ is the heat conduction from "al" to "ig"; $A_{p}$ and $A_{a l}$ are the areas of "p" and "al", respectively.

The heat balance at PV module is given by

$$
0=(\beta \tau)_{c} G f_{c} A_{p}+(\beta \tau)_{p} G_{c}\left(1-f_{c}\right) A_{p}-E-q_{d, p-a l} A_{p}-q_{r, p-i g} A_{p}-q_{d, p-i g} A_{p}
$$

where $(\beta \tau)_{c}$ and $(\beta \tau)_{p}$ are the effective absorbance of the solar cells "c" and PV base plate, respectively; $q_{d, p-a l}$ is the heat conduction from "p" to "al”; $E$ is the electricity generation.

The heat balance at the aluminium sheet is given by

$$
0=q_{d, p-a l} A_{p}-q_{d, a l-c o} A_{a l-c o}-q_{r, a l-i g} A_{a l}-q_{d, a l-i g} A_{a l}
$$

where $A_{a l-c o}$ is the contact area between "al" and copper tube "co"; $q_{d, a l-c o}$ is the heat conduction from "al" to the copper tube "co".

The heat balance at the copper tube can be expressed by

$$
0=q_{d, a l-c o} A_{a l-c o}-q_{v, c o-r} A_{i, c o}
$$

where $A_{i, c o}$ is the internal surface area of "co"; $q_{v, c o-r}$ is the heat convection from "co" to the refrigerant "r".

The heat balance at the refrigerant can be expressed by

$$
0=q_{c o-r} A_{i, c o}-m_{r} \Delta h_{r}
$$

where $m_{r}$ is the mass flow rate of the refrigerant for each PV/T collector; $\Delta h_{r}$ is the refrigerant enthalpy difference between collector inlet and outlet.

Neglecting the pressure drop in the discharge line, the relationship been the temperature and pressure at the discharge and suction sides of the compressor can be expressed by 


$$
T_{\text {dis }}=T_{\text {suc }}\left(\frac{p_{\text {dis }}}{p_{\text {suc }}}\right)^{\frac{\kappa-1}{\kappa}}
$$

where $T_{\text {dis }}$ and $T_{\text {suc }}$ are the discharge and suction temperatures, respectively; $P_{\text {dis }}$ and $P_{\text {suc }}$ are the discharge and suction pressures, respectively.

The throttling process is regarded as the isenthalpic one. The mass flow rate is given by

$$
m_{r}=k_{e x} \sqrt{\rho_{r}\left(p_{c d}-p_{e v}\right)}
$$

where $k_{e x}$ is the characteristic constant of the valve; $p_{c d}$ and $p_{e v}$ are the condensing and evaporating pressure respectively; $\rho_{r}$ is the density of refrigerant liquid.

The condensing temperature is kept at $45{ }^{\circ} \mathrm{C}$. The heat balance equations at the refrigerant side of the condenser are similar to that when it flows through the PV/T evaporator. At the water side of the condenser, the heat balance can be expressed by [10]

$$
0=m_{w} C p_{w}\left(T_{w, \text { out }}-T_{w, \text { in }}\right)-\alpha_{w-h x} A_{w-h x}\left(T_{w, \text { out }}-T_{w, \text { in }}\right) / \ln \left(\frac{T_{h x}-T_{w, \text { in }}}{T_{h x}-T_{w, \text { out }}}\right)
$$

where $m_{w}$ is the water flow rate; $C p_{w}$ is the specific heat of water; $T_{w, o u t}$ and $T_{w, i n}$ are the water temperature at the outlet and inlet respectively; $\alpha_{w-h x}$ is the convective heat transfer coefficient between water and the heat exchanger plate; $A_{w-h x}$ is the contact area between water and the heat exchanger plate; $T_{h x}$ is the temperature of the heat exchanger plate.

\section{Results and Analysis}

The numerical simulation is carried out based on the climatic data of London, UK. The PV/T evaporator is assumed to be south-facing with a tilt angle of $30^{\circ}$. EES (Engineering Equation Solver) is used for the calculation. The climatic data including monthly mean horizontal solar radiation and air temperature is obtained from the British Atmospheric Data Centre and the horizontal solar radiation is converted to that on tilt surface for calculation.

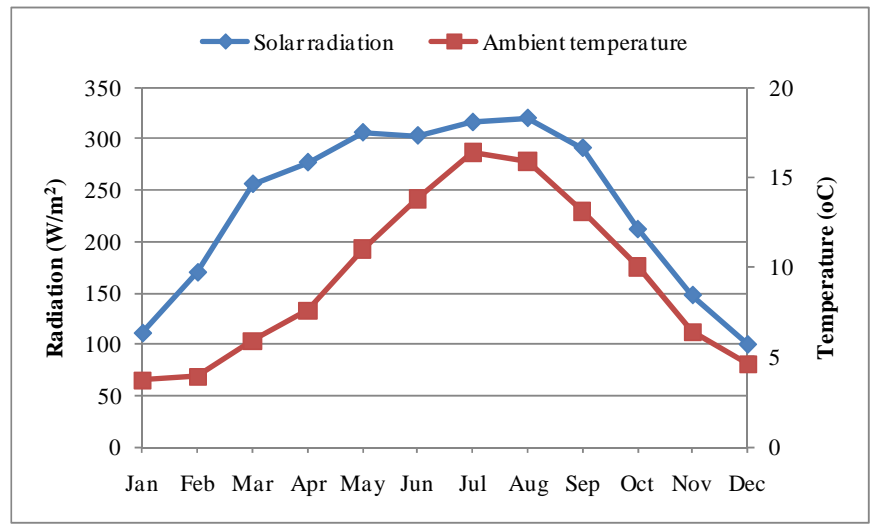

Fig. 2. The monthly mean solar radiation and ambient temperature

\subsection{Solar radiation and ambient temperature}

Fig. 2 shows the monthly mean solar radiation on tilt surface with an angle of $30^{\circ}$ and ambient temperature. It can be seen that the monthly mean solar radiation increases sharply from January to May and fluctuates 
around $300 \mathrm{~W} / \mathrm{m}^{2}$ from May to August, then decreases sharply from August to December. The maximum solar radiation is $320 \mathrm{~W} / \mathrm{m}^{2}$ occurred in August and the minimum is $100 \mathrm{~W} / \mathrm{m}^{2}$ in December. The annual mean solar radiation is $234 \mathrm{~W} / \mathrm{m}^{2}$. The ambient temperature increases sharply from $3.7{ }^{\circ} \mathrm{C}$ in January to $16.4{ }^{\circ} \mathrm{C}$ in July, and then decreases sharply to $4.6{ }^{\circ} \mathrm{C}$ in December. The annual mean ambient temperature is $9.4{ }^{\circ} \mathrm{C}$.

\subsection{Thermal performance of the PV/T evaporator}

Fig. 3 shows the monthly mean thermal efficiency and heat gain of the PV/T evaporator. The curve for the heat gain of evaporator has the same trend as that of solar radiation. The minimum heat gain of 40 $\mathrm{W} / \mathrm{m}^{2}$ also occurs in December with the minimum solar radiation and the maximum heat gain of $139 \mathrm{~W} / \mathrm{m}^{2}$ (PV area) also occurs in August with the maximum solar radiation. The thermal efficiency varies from 0.58 in January to 0.697 in July with an average of 0.659 , which is much higher than that of the conventional flat plate PV/T panels, due to the reduction of heat loss to the ambient by vacuum glass tubes. From Fig.2 it can be seen that the solar radiation in January is slightly higher than that in December, while the ambient temperature in January is slightly lower than that in December. So it can be concluded that the thermal efficiency is mainly affected by the ambient temperature.

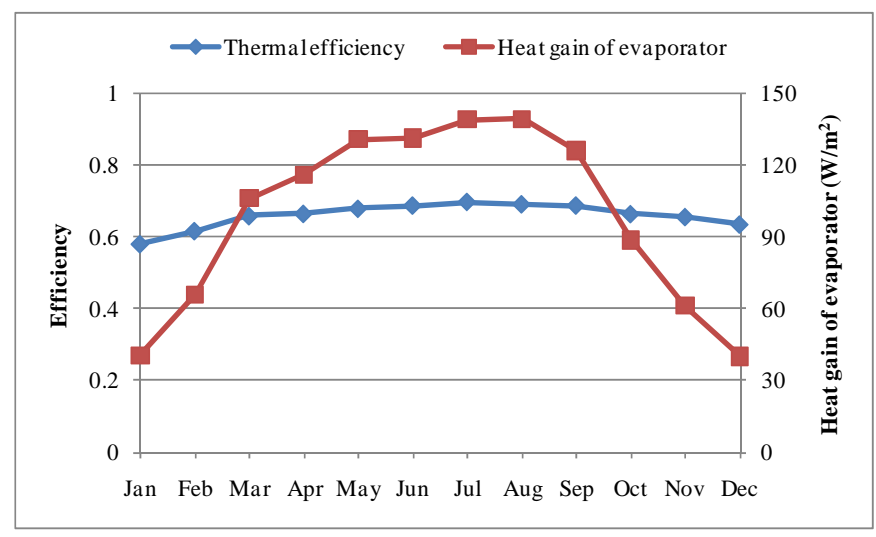

Fig. 3. The monthly mean thermal efficiency and heat gain of evaporator

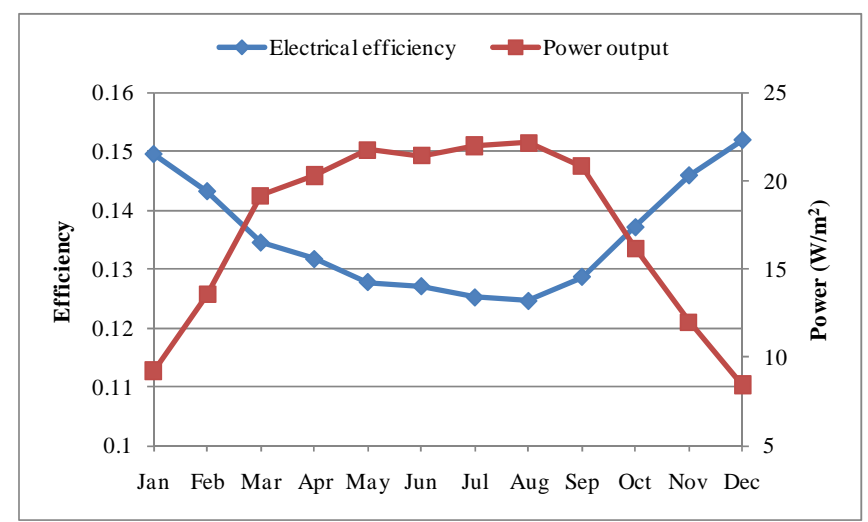

Fig. 4. The monthly mean electrical efficiency and power output

\subsection{Electrical performance of the PV/T evaporator}

Fig. 4 shows the monthly mean electrical efficiency and power output of the PV/T evaporator. It can be seen that the electrical efficiency decreases sharply from 0.15 in January to 0.125 in August, and then increases sharply to 0.152 in December, with an average of 0.136. Compared with the solar radiation in Fig.2, it can be found that the maximum electrical efficiency occurs in December with the minimum 
radiation, while the minimum electrical efficiency occurs in August with the maximum radiation. The electrical efficiency is mainly affected by solar radiation and it decreases with the increase in solar radiation. The power output of the PV/T evaporator increases with the increase in solar radiation. It varies from $8.4 \mathrm{~W} / \mathrm{m}^{2}$ (PV area) to $22.28 .4 \mathrm{~W} / \mathrm{m}^{2}$ with an average of $17.3 \mathrm{~W} / \mathrm{m}^{2}$, which should be much higher in some low latitude locations with higher solar radiation.

\subsection{COP and condenser capacity}

Fig. 5 shows the monthly mean COP and condenser capacity of the GVT PV/T heat pump system. The COP varies from 3.0 in December to 4.5 in August with an average of 3.8. It is could be much higher under higher solar radiation. The condenser capacity ranging from $59.4 \mathrm{~W} / \mathrm{m}^{2}$ (PV area) to $178.9 \mathrm{~W} / \mathrm{m}^{2}$ would provide the heat source for space heating and domestic hot water.

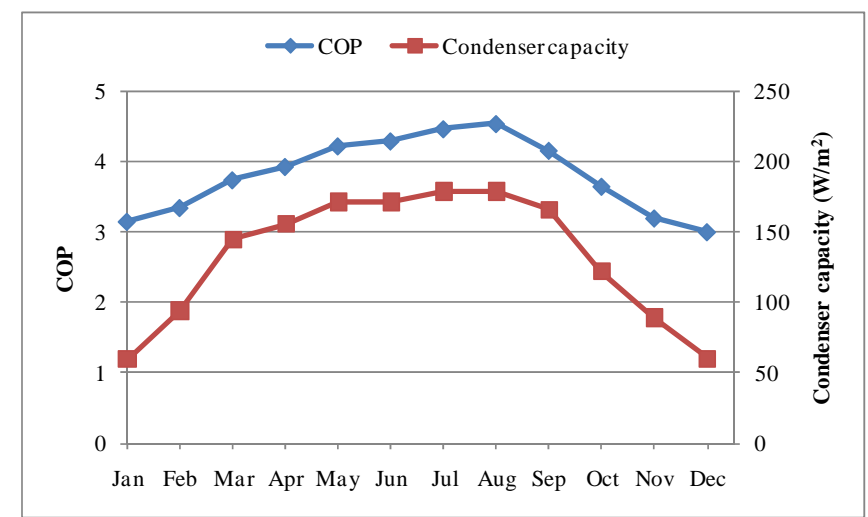

Fig. 5. The monthly mean COP and condenser capacity

\section{Conclusions}

A novel DX-PV/T heat pump system is introduced in this paper. Numerical steady models have been established for each component of the heat pump system and part of the PV/T-sandwich collector/evaporator for predicting their energy performance under the climatic conditions of London, UK. From the simulation results, it can be concluded as follow.

(1) The PV/T evaporator in the novel PV/T heat pump system has a better energy performance than the typical air-cooled or water-cooled flat plate PV collectors due to the vacuum insulation for the reduced heat loss and the lower boiling temperature of R134a for better heat extraction from PV modules.

(2) The monthly mean thermal efficiency is mainly affected by the ambient temperature. It varies from 0.58 in January to 0.697 in July with an average of 0.659 . The monthly mean electrical efficiency is mainly affected by the solar radiation. It varies from 0.125 in August to 0.152 in December with an average of 0.136 .

(3) The novel PV/T heat pump system has a COP ranging from 3.0 to 4.5 with an average of 3.8. The condenser capacity ranging from $59.4 \mathrm{~W} / \mathrm{m}^{2}$ to $178.9 \mathrm{~W} / \mathrm{m}^{2}$ would provide the heat source for space heating and domestic hot water. The energy performance of the novel PV/T heat pump system should be much better in some low latitude locations with higher solar radiation.

\section{Acknowledgements}

The work of this paper is fully supported by Funding Project for New Star of Scientific and Technical Research of Beijing (2011029) and Beijing Municipal Key Lab of HVAC (KF201004). 


\section{References}

[1] PVT Forum. PVT Roadmap - a European guide for the development and market introduction of PV-thermal technology. 2006.

[2] Niccolo A, Giancarlo C, Francesco V. Design, development and performance monitoring of a photovoltaic-thermal (PVT) air collector. Renewable Energy, 2008; 33(5):914-927.

[3] Tonui JK, Tripanagnostopoulos Y. Improved PV/T solar collectors with heat extraction by forced or natural air circulation. Renewable Energy, 2007; 32(4):623-637.

[4] Dubey S, Tiwari GN. Thermal modeling of a combined system of photovoltaic thermal (PV/T) solar water heater. Solar Energy, 2008; 82(7):602-612.

[5] Chow T, He W, Ji J, Chan ALS. Performance evaluation of photovoltaic-thermosyphon system for subtropical climate application.Solar Energy, 2007; 81(1):123-130.

[6] Tripanagnostopoulos Y. Aspects and improvements of hybrid photovoltaic/thermal solar energy systems. Solar Energy, 2007; 81(9):1117-1131.

[7] Ji J, Liu K, Chow T, Pei G, He W, He H. Performance analysis of a photovoltaic heat pump. Applied Energy, 2008; 85(8):680690.

[8] Zondag HA, de Vries DW, van Helden WGJ, et al. The yield of different combined PV-thermal collector designs. Solar Energy, 2003; 74(3):253-269.

[9] Ji J, He H, Chow T, Pei G, He W, Liu K. Distributed dynamic modelling and experimental study of PV evaporator in a PV/T solar-assisted heat pump. International Journal of Heat and Mass Transfer, 2009; 52(5-6):1365-1373.

[10] Duffie JA, Beckman WA. Solar Engineering of Thermal Processes. 3rd ed. New York: Wiley, 2006. 